\title{
Antiemetic efficacy of single-dose palonosetron and dexamethasone in patients receiving multiple cycles of multiple day-based chemotherapy
}

\author{
Vito Lorusso • Marianna Giampaglia • \\ Luciana Petrucelli • Valeria Saracino • Tania Perrone • \\ Antonio Gnoni
}

Received: 26 July 2011 / Accepted: 9 April 2012 /Published online: 26 April 2012

(C) The Author(s) 2012. This article is published with open access at Springerlink.com

\begin{abstract}
Introduction The goal of pharmacological prophylaxis of chemotherapy-induced nausea and vomiting (CINV) should be the elimination of both nausea and vomiting symptoms during all planned chemotherapy cycles. The aim of this study was to assess the efficacy of a single dose of palonosetron and dexamethasone to prevent CINV and to guarantee an adequate food intake (FI) in patients receiving several cycles of multiple day-based chemotherapy (MD-CT).

Methods Patients with advanced cancer but without a compromised nutritional status (bone mass index $\geq 18.5$ ) were treated with $0.25 \mathrm{mg}$ palonosetron plus $20 \mathrm{mg}$ dexamethasone before MD-CT. The MD-CT regimen was either epirubicin plus ifosfamide or paclitaxel plus cisplatin and ifosfamide. Nausea, vomiting, and FI were monitored in a 7-day diary. Complete response (CR: no vomiting and no rescue therapy) was the primary endpoint, while complete control (CC: CR and no more than mild nausea) and the evaluation of FI were secondary endpoints. The endpoints were evaluated during the overall timescale (0-168 h) of the chemotherapy regimen. Results Fifty patients were enrolled, $80 \%$ of whom achieved CR and 78\% achieved CC. During the six chemotherapy cycles, CR and CC ranged from $76 \%$ to $88 \%$ and from $62 \%$ to $88 \%$, respectively. Moreover, patients with CR had a significantly $(p<0.0001)$ higher weekly food intake compared with patients not achieving CR.
\end{abstract}

\footnotetext{
V. Lorusso $(\varangle) \cdot$ M. Giampaglia $\cdot$ L. Petrucelli $\cdot$ V. Saracino

A. Gnoni

Oncology Unit, Vito Fazzi Hospital,

Lecce, Italy

e-mail: vitolorusso@inwind.it

T. Perrone

Scientific Department, Italfarmaco,

Cinisello Balsamo, MI, Italy
}

Conclusions This trial was the first to assess the efficacy of palonosetron and dexamethasone for the prevention of both nausea and vomiting in patients receiving multiple cycles of MD-CT. In this trial, the ability of patients to intake an adequate amount of food each week was correlated with nausea, thus providing clinicians with an objective parameter for the measurement of the effects of nausea. A single dose of palonosetron and dexamethasone was able to prevent CINV in most patients receiving 3 days of chemotherapy during all planned chemotherapy cycles.

Keywords Chemotherapy-induced nausea and vomiting $(\mathrm{CINV}) \cdot$ Food intake $\cdot$ Multiple day chemotherapy $\cdot$ Multiple cycles $\cdot$ Palonosetron

\section{Introduction}

Prevention, rather than treatment, is the principal aim of antiemetic prophylaxis in patients undergoing chemotherapy [1]. Control of chemotherapy-induced nausea and vomiting (CINV) is necessary to maintain an adequate quality of life and to guarantee the completion of treatment during all planned chemotherapy cycles [1]. Few studies have assessed the efficacy of antiemetic prophylaxis over multiple chemotherapy cycles [2-4]. It is also well-known that patients who are not adequately protected from nausea and vomiting during the first chemotherapy cycle are at a higher risk of developing anticipatory emesis in subsequent cycles [5]. As a consequence, CINV control becomes more difficult.

Risk factors for CINV are both patient- and chemotherapyrelated: female gender, young age, motion sickness, and no alcohol consumption are patient risk factors while the 
emetogenic potential of the chemotherapy drug and multiple day (MD) and/or high dose administration are chemotherapyrelated risk factors $[6,7]$.

Patients treated with MD chemotherapy (MD-CT) are at risk from CINV throughout the entire treatment period because continuous daily emetogenic stimuli make antiemetic prophylaxis quite problematic [7]. For CINV prophylaxis in patients receiving MD-CT, antiemetic guidelines suggest the use of a single dose of palonosetron, a second-generation 5-HT3 receptor antagonist (5-HT3RA), instead of multiple daily doses of first generation 5-HT3RAs (ondansetron, granisetron, tropisetron), with the addition in both cases of dexamethasone [8, 9].

Palonosetron demonstrated superior results in preventing CINV in high (HEC) and moderately (MEC) emetogenic chemotherapy compared with first-generation 5-HT3RAs [10-14]. Indeed, besides controlling vomiting, palonosetron in combination with dexamethasone, as compared with other antiemetic drugs [14-16], is also better at controlling nausea and can guarantee an adequate caloric intake during the 7-day period following the first chemotherapy cycle [17]. In a previous study, we proposed the use of a nutritional diary for the measurement of caloric intake, to more objectively define the impact of nausea on the patient's quality of life. In our hands, this tool provided an objective measurement of the improvement of patient's quality of life induced by the pharmacological prophylaxis.

The antiemetic efficacy of palonosetron has routinely been assessed during the first chemotherapy cycle [5, 7]; however, no published clinical trial has evaluated its prospective efficacy over the course of the entire patient treatment plan. However, a recent survey assessed the safety of palonosetron administered over multiple cycles of 1-day MEC and HEC, demonstrating that it was well tolerated, with no unexpected treatment adverse events in later cycles [18].

The aim of this study was to therefore assess the efficacy of a single dose of palonosetron and dexamethasone to prevent CINV, in order to ensure adequate food intake, in patients receiving numerous cycles of MD-CT.

\section{Patients and methods}

The study presented here describes a prospective, uncontrolled trial conducted in the Oncology Department of the Vito Fazzi Hospital in Lecce, Italy. The study was approved by the local ethic committee, and all patients signed the informed consent form.

Eligible cancer patients receiving MD-CT were enrolled in the study. The main inclusion criteria were: age $>18$ years old; ECOG 0-1; normal renal and liver function; no uncontrolled vomiting; and absence of intestinal obstruction, peritonitis, serious mucositis, and infections.
A nutritional assessment was performed for each patient, and all eligible patients were required to have a moderate or well-nourished nutritional status according to the subjective global assessment (SGA). In addition, a bone mass index $(\mathrm{BMI}) \geq 18.5$ was required.

The MD-CT regimen was either EPI-IFO (epirubicin plus ifosfamide) or TIP (paclitaxel plus cisplatin and ifosfamide). Refer to Table 1 for the study treatment flow chart.

Patients received an antiemetic treatment of a single palonosetron bolus, $0.25 \mathrm{mg}$ iv, over $30 \mathrm{~s}$, and a single dose of dexamethasone, $20 \mathrm{mg}$, both administered $30 \mathrm{~min}$ prior to the administration of chemotherapy. The same antiemetic therapy was administered before each planned chemotherapy cycle.

All patients maintained a diary from day 1 until day 7. The study diary was organized with both an emesis and a nutrition-specific section, as reported in a previous publication [17]. In the emesis section, patients recorded each episode of vomiting, nausea experienced, and any use of rescue medication. In the nutritional section, patients had to quote their daily food intake, the time food was consumed, and the amount of each portion eaten. The amount of portions was quantified using pictures of standard portions included in the diary. The diary had to be completed from day 1 (day of first chemotherapy administration) until day $7(168 \mathrm{~h}$ after chemotherapy administration). On day 8, the patient returned the diary to the investigator and discussed with

Table 1 Chemotherapy regimens, antiemetic prophylaxis, and study assessments

\begin{tabular}{llllllll}
\hline Variable & D1 & D2 & D3 & D4 & D5 & D6 & D7 \\
\hline Chemotherapy regimens & & & & & & & \\
EPI-IFO & & & & & & & \\
Epirubicin $60 \mathrm{mg} / \mathrm{m}^{2}$ & $\mathrm{X}$ & & & & & \\
Ifosfamide $3 \mathrm{~g} / \mathrm{m}^{2}$ & $\mathrm{X}$ & $\mathrm{X}$ & $\mathrm{X}$ & & & \\
TIP & & & & & & \\
Paclitaxel $175 \mathrm{mg} / \mathrm{m}^{2}$ & $\mathrm{X}$ & & & & & & \\
Cisplatin $75 \mathrm{mg} / \mathrm{m}^{2}$ & & $\mathrm{X}$ & & & & & \\
Ifosfamide $1,5 \mathrm{~g} / \mathrm{m}^{2}$ & $\mathrm{X}$ & $\mathrm{X}$ & $\mathrm{X}$ & & & & \\
Antiemetic prophylaxis & & & & & & & \\
Palo 0.25 mg & $\mathrm{X}$ & & & & & & \\
Dex 20 mg & $\mathrm{X}$ & & & & & & \\
Study evaluations & & & & & & & \\
CINV & $\mathrm{X}$ & $\mathrm{X}$ & $\mathrm{X}$ & $\mathrm{X}$ & $\mathrm{X}$ & $\mathrm{X}$ & $\mathrm{X}$ \\
FI & $\mathrm{X}$ & $\mathrm{X}$ & $\mathrm{X}$ & $\mathrm{X}$ & $\mathrm{X}$ & $\mathrm{X}$ & $\mathrm{X}$ \\
\hline
\end{tabular}

Abbreviations: $D$ day, Palo palonosetron, Dex dexamethasone, CINV chemotherapy-induced nausea and vomiting, $F I$ food intake, EPI-IFO epirubicine plus ifosfamide, TIP paclitaxel, cisplatin, and ifosfamide 
him all entries regarding CINV information. The nutritional expert then reviewed and discussed all nutritional data.

All patients were monitored for a maximum of six chemotherapy cycles.

\section{Endpoints}

Primary and secondary endpoints were evaluated during the 7 days following the first chemotherapy administration: overall phase $(0-168 \mathrm{~h})$. The primary endpoint of the study was the percentage of patients with complete response (CR), defined as no vomiting and no use of rescue medication. Secondary endpoints were: complete control (CC), totally control (TC), and impact of nausea severity and CR on weekly food intake. CC was defined as no vomiting, no rescue medication, and no more than mild nausea; TC was defined as no vomiting, no rescue, and no nausea. Severity of nausea was evaluated using a four-point Likert scale ranging from 0 (none) to 3 (severe). Among the $\mathrm{CC}$ patients, the impact of residual nausea on weekly food intake was evaluated, comparing the CC patients with mild nausea versus the CC patients with no mild nausea.

All patients who started the first chemotherapy cycle were evaluated throughout all subsequent cycles (maximum six cycles).

Treatment safety was evaluated during all chemotherapy cycles, and all adverse events were recorded and graded according to the common terminology criteria for adverse events (CTCAE) described by the National Cancer Institute, version 4.0. (http://ctep.cancer.gov/ forms/CTCAEv4.pdf).

\section{Statistical analysis}

The demographic and clinical-pathological characteristics were summarized by means of descriptive statistics. In general, absolute and relative frequencies were employed to summarize qualitative variables, while arithmetic mean, standard deviation (SD), median, and range were used to summarize quantitative data.

Main and sub-group comparisons were tested using oneway analysis of variance for continuous variables. The relationship between weekly intake (kilocalories) and nausea scores was investigated by means of linear correlation analysis. Due to the supportive and exploratory nature of these comparisons, no adjustments for multiplicity were performed for the multiple comparisons across cycles, endpoints, and sub-groups. Differences were considered to be statistical significant for two-tailed $p$ values $\leq 0.05$. All statistical computations were carried out using the SAS system version 9.1.3.

\section{Results}

Between July 2008 and January 2010, 50 consecutive patients were enrolled and evaluated. Most participants were female $(82 \%)$, chemo-naïve $(74 \%)$, with a diagnosis of soft tissue sarcoma $(52 \%)$. All patients received at least two consecutive chemotherapy cycles, and half $(50 \%)$ completed the six planned chemotherapy cycles. None of the patients were severely malnourished; the majority had an adequate appetite (median apVAS 7) and a median BMI of 26 (range, 18.5-30.5). Baseline patient characteristics and nutritional status are reported in Table 2.

Table 2 Baseline patient characteristics and nutritional status

Number of patients, 50

\begin{tabular}{|c|c|}
\hline \multicolumn{2}{|l|}{ Age, years } \\
\hline Median (range) & $56.8(33-81)$ \\
\hline \multicolumn{2}{|l|}{ Gender \% $(N)$} \\
\hline Male & $18(9)$ \\
\hline Female & $82(41)$ \\
\hline \multicolumn{2}{|l|}{ Diagnosis $\%(N)$} \\
\hline Soft tissue sarcoma & $52(26)$ \\
\hline Cervix & $34(17)$ \\
\hline Bladder & $6(3)$ \\
\hline Breast & $6(3)$ \\
\hline Lung & $2(1)$ \\
\hline \multicolumn{2}{|l|}{ Previous Treatment $\%(N)$} \\
\hline Naive & $74(37)$ \\
\hline Not naive & $26(13)$ \\
\hline \multicolumn{2}{|l|}{ Chemotherapy regimen $\%(N)$} \\
\hline Ifosfamide-epirubicin regimens & $68(34)$ \\
\hline Cisplatin-based regimen $>50 \mathrm{mg} / \mathrm{mq}$ & $32(16)$ \\
\hline \multicolumn{2}{|l|}{ Number of chemotherapy cycles $\%(N)$} \\
\hline 1 & $100(50)$ \\
\hline 2 & $100(50)$ \\
\hline 3 & $94(47)$ \\
\hline 4 & $76(38)$ \\
\hline 5 & $50(25)$ \\
\hline 6 & $50(25)$ \\
\hline \multicolumn{2}{|l|}{ Nutritional status at baseline } \\
\hline \multicolumn{2}{|l|}{ BMI value } \\
\hline Median (range) & $26(18.5-30.5)$ \\
\hline \multicolumn{2}{|l|}{ apVAS value } \\
\hline Median (range) & $7(3-10)$ \\
\hline \multicolumn{2}{|l|}{ SGA, \% $(N)$} \\
\hline A, well nourished & $84(42)$ \\
\hline $\mathrm{B}$, moderately nourished & $16(8)$ \\
\hline $\mathrm{C}$, severely nourished & 0 \\
\hline
\end{tabular}

$B M I$ body mass index, apVAS visual analogue scale to assess appetite, $S G A$ subjective global assessment 
During the six consecutive chemotherapy cycles CR, CC, and TC ranged from $76 \%$ to $88 \%$, from $62 \%$ to $88 \%$ and from $54 \%$ to $80 \%$, respectively (Fig. 1 ). The severity of nausea had a direct impact on food intake $\left(R^{2}=0.72\right)$ (Fig. 2). The percentage of emesis-free patients was $76 \%$ (38/50) during the first chemotherapy cycle; $86 \%(43 / 50)$, $89.4 \%$ (42/47), $86.8 \%$ (33/38) during the second, third, and fourth cycle, respectively; and $88 \%$ (22/25) during the final two cycles.

The correlation between the severity of nausea and the amount of weekly food intake remained uniform during all subsequent chemotherapy cycles (Fig. 3). During cycles 5 and 6 , no patient experienced any nausea of moderate severity.

During all chemotherapy cycles (Table 3), CR patients always had a significantly higher weekly food intake than patients who experienced vomiting and/or used rescue medication $(p=<0.0001)$.

The impact of mild nausea on food intake was evaluated in the CC population. CC patients who experienced no nausea had a median weekly food intake ranging from 11,102 to $12,200 \mathrm{kcal}$ during multiple chemotherapy cycles, whereas CC patients with symptoms of mild nausea had a median weekly food intake ranging from 8,500 to $9,800 \mathrm{kcal}$. The difference between the two groups (minimum 2,102 to maximum $2,957 \mathrm{kcal}$ ) was statistically significant during all chemotherapy cycles (Table 4). None of the patients experienced mucositis during chemotherapy treatment.

\section{Discussion}

The elimination of vomiting and symptoms of nausea should be the goal of antiemetic prophylaxis, not only during the first course of chemotherapy, but also during all planned cycles [1].

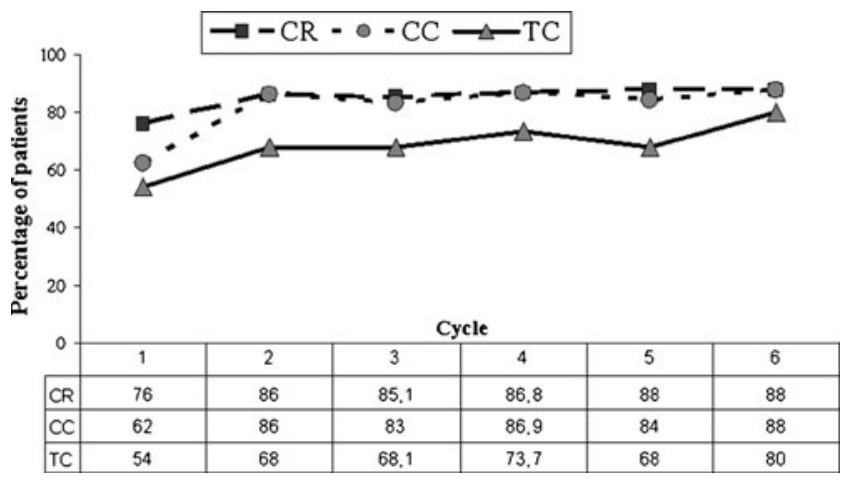

Fig. 1 Percentage of patients achieving a complete response ( $C R$ no vomiting and no rescue medication), a complete control ( $C C$ no vomiting, no rescue medication and no more than mild nausea), and total control (TC no vomiting, no rescue, and no nausea) during the six chemotherapy cycles

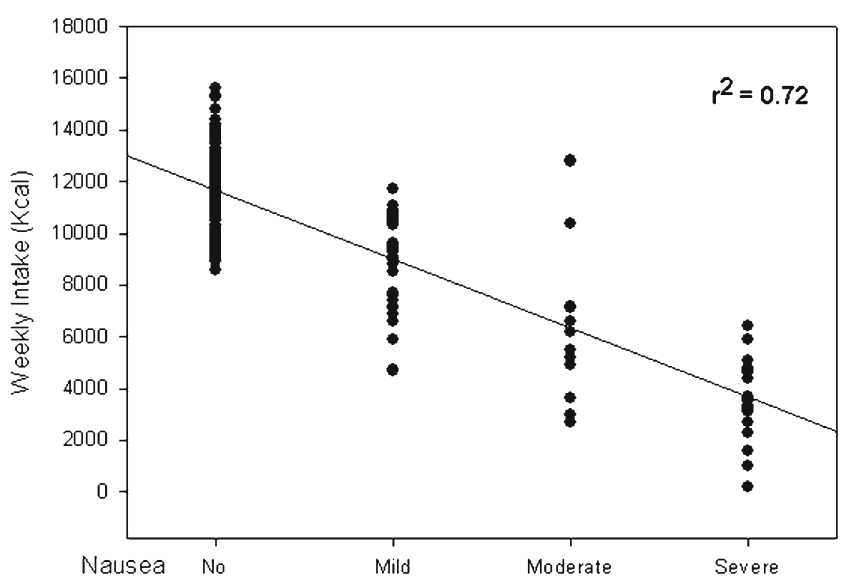

Fig. 2 Impact of nausea on food intake during six consecutive chemotherapy cycles

Vomiting and nausea still rank among the five most distressing symptoms among cancer patients receiving chemotherapy $[19,20]$. In this study, we assessed for the first time the antiemetic efficacy of a single dose of palonosetron and dexamethasone in patients receiving multiple cycles of MD-CT.

For patients receiving MD-CT, the control of CINV is more difficult to achieve due to continuous daily emetic stimuli, especially since acute and delayed emesis may overlap. Antiemetic guidelines for the treatment of MDCT suggest the administration of a 5-HT3RA once daily at the time of chemotherapy administration and for 2-3 days following the end of treatment. A single intravenous palonosetron dose could be used instead of multiple daily doses of old generation 5-HT3RAs [7, 8]. This was suggested following recent clinical trials, which assessed the efficacy of single and multiple doses of palonosetron both in oncological [17, 21, 22] and hematological [23] MD-CT settings. It has previously been demonstrated that the use of palonosetron can also reduce the use of dexamethasone in antiemetic prophylaxis in patients receiving MEC and AC-based (doxorubicin and cyclophosphamide) chemotherapy [24, 25]. In

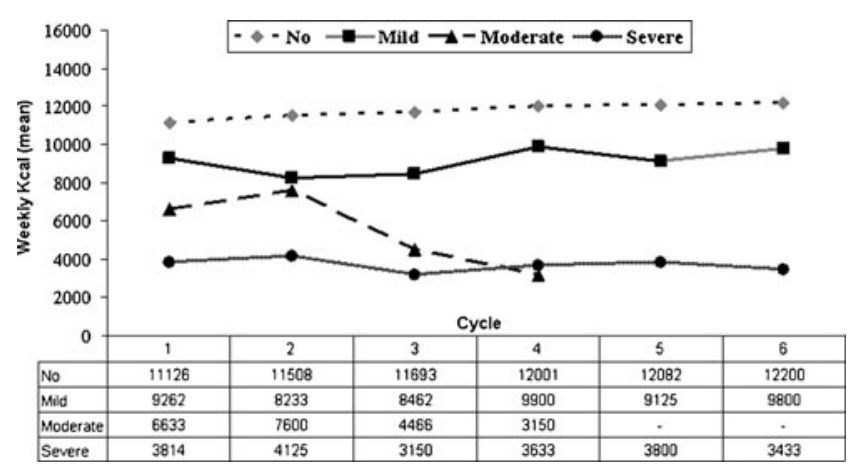

Fig. 3 Impact of severity of nausea on weekly food intake during 6 consecutive chemotherapy cycles 
Table 3 Amount of weekly food intake (expressed in kilocalories) related to complete response during all evaluated chemotherapy cycles

CR complete response (no vomiting and no use of rescue medication), $S D$ standard deviation, $N$ number of patients

\begin{tabular}{lccc}
\hline Weekly kilocalories & CR, yes & CR, no & $P$ value \\
\hline Cycle 1, mean \pm SD $(N)$ & $10,725 \pm 1,726.49(38)$ & $5,766.67 \pm 3,049.69(12)$ & $<.0001$ \\
Cycle 2, mean \pm SD $(N)$ & $10,927.91 \pm 1,962.61(43)$ & $4,971.43 \pm 1,939.69(7)$ & $<.0001$ \\
Cycle 3, mean \pm SD $(N)$ & $11,002.56 \pm 1,981.29(39)$ & $6,314.29 \pm 4,486.06(7)$ & $<.0001$ \\
Cycle 4, mean \pm SD $(N)$ & $11,683.33 \pm 1,697.55(33)$ & $3,440 \pm 999(5)$ & $<.0001$ \\
Cycle 5, mean \pm SD $(N)$ & $11,577.27 \pm 1,770.91(22)$ & $3,800 \pm 556.78(3)$ & $<.0001$ \\
Cycle 6, mean \pm SD $(N)$ & $11,763.64 \pm 1,573.07(11)$ & $3,433.33 \pm 1,059.87(3)$ & $<.0001$ \\
\hline
\end{tabular}

our trial, the administration of dexamethasone was limited to day 1 only. The reduction of dexamethasone dosing for the prevention of CINV is of particular clinical interest since it has been demonstrated that side effects related to steroid use are likely to accumulate over multiple cycles of chemotherapy [26].

The results of our study suggest that a single dose of palonosetron plus dexamethasone can achieve a high control of CINV during all planned MD-CT cycles, which also confirms the efficacy of palonosetron in maintaining an adequate food intake during all courses. Recently, a survey identified fatigue, appetite loss, and nausea as the most distressing symptoms experienced by cancer patients [20]. These symptoms persist throughout the treatment period and are reported earlier and more frequently by patients than clinicians. In this survey, the cumulative incidence of moderate-to-severe nausea is similar to that of moderate-to-severe appetite loss, suggesting a strict correlation between these two adverse events [20]. In our trial, the correlation between severity of nausea and weekly caloric intake is maintained during all chemotherapy cycles. The patients' ability to enjoy a meal, even during the week of chemotherapy administration, is necessary to relieve symptoms and to guarantee the completion of the planned cancer treatment. The administration of first-generation 5HT3RAs together with dexamethasone has improved the control of vomiting, and their introduction into routine oncology practices was a key advance, along with other supportive care, towards a major shift in oncology care in the ambulatory setting [27]. However, the control of nausea still remains suboptimal and the impact of residual nausea on patients' health and quality of life should not be underestimated. Our study (Table 4) highlighted that residual episodes of nausea - no matter how mild-significantly affected the patients' nutritional status as their weekly food intake was reduced throughout the entire chemotherapy treatment. Indeed, the control of nausea still remains an unmet need in cancer patients receiving chemotherapy.

The role of palonosetron in antiemetic MD-CT prophylaxis, where acute and delayed CINV overlap, is probably explained by its unique pharmacological properties. Palonosetron has a longer half-life (40 h) [28] and a greater receptor binding affinity (>30-fold) than other 5-HT3RAs [29]. Moreover, palonosetron exhibits allosteric interactions [30], triggers receptor internalization, and exhibits prolonged inhibition of receptor function [31]. Palonosetron is the only antiemetic drug that has been demonstrated to ensure an adequate amount of weekly food intake during all chemotherapy cycles due to its ability to control nausea besides vomiting.

Larger and randomized studies are granted to define the role of nausea and vomiting on ability of patients to intake an adequate amount of food during chemotherapy administration, both in MD- and single day-CT.

In conclusion, this study demonstrates that palonosetron and dexamethasone are effective in the prevention of both vomiting and nausea in patients receiving multiple day-based chemotherapy and that this effect is sustained throughout the entire chemotherapy treatment program.
Table 4 Impact of mild nausea on weekly food intake among the $\mathrm{CC}$ population during the all six chemotherapy cycles

\begin{tabular}{|c|c|c|c|c|}
\hline Cycle & Complete control & Weekly kilocalories (mean) & Difference (weekly kilocalories) & $P$ value \\
\hline 1 & $\begin{array}{l}\text { No nausea } \\
\text { Mild nausea }\end{array}$ & $\begin{array}{r}11,102 \\
8,500\end{array}$ & 2,602 & 0.0025 \\
\hline 2 & $\begin{array}{l}\text { No nausea } \\
\text { Mild nausea }\end{array}$ & $\begin{array}{r}11,509 \\
8,733\end{array}$ & 2,776 & $<0.0001$ \\
\hline 3 & $\begin{array}{l}\text { No nausea } \\
\text { Mild nausea }\end{array}$ & $\begin{array}{r}11,632 \\
9,000\end{array}$ & 2,632 & 0.0001 \\
\hline 4 & $\begin{array}{l}\text { No nausea } \\
\text { Mild nausea }\end{array}$ & $\begin{array}{r}12,002 \\
9,900\end{array}$ & 2,102 & 0.0085 \\
\hline 5 & $\begin{array}{l}\text { No nausea } \\
\text { Mild nausea }\end{array}$ & $\begin{array}{r}12,082 \\
9,125\end{array}$ & 2,957 & 0.0010 \\
\hline 6 & $\begin{array}{l}\text { No nausea } \\
\text { Mild nausea }\end{array}$ & $\begin{array}{r}12,200 \\
9,800\end{array}$ & 2,400 & 0.0431 \\
\hline
\end{tabular}


Conflicts of interest TP is employee in the Scientific Department of Italfarmaco S.p.A.

Open Access This article is distributed under the terms of the Creative Commons Attribution License which permits any use, distribution, and reproduction in any medium, provided the original author(s) and the source are credited.

\section{References}

1. Hesketh PJ (2008) Chemotherapy-induced nausea and vomiting. N Engl J Med 358(23):2482-2494

2. De Wit R, Van Den Berg H, Burghouts J et al (1998) Initial high anti-emetic efficacy of granisetron with dexamethasone is not maintained over repeated cycles. Brit J Cancer 77(9):1487-1491

3. Sigsgaard T, Herrstedt J, Handberg J et al (2001) Ondansetron plus metopimazine compared with ondansetron plus metopimazine plus prednisolone as antiemetic prophylaxis in patients receiving multiple cycles of moderately emetogenic chemotherapy. J Clin Oncol 19(7):2091-2097

4. De Wit R, Herrstedt J, Rapoport B et al (2003) Addition of the oral NK 1 antagonist aprepitant to standard antiemetics provides protection against nausea and vomiting during multiple cycles of cisplatin-based chemotherapy. J Clin Oncol 21:4105-4111

5. Celio L, Denaro A, Canova S, Gevorgyan A, Bajetta E (2008) Clinical update on palonosetron in the management of chemotherapy-induced nausea and vomiting. Tumori 94:447-452

6. Navari RM (2007) Prevention of emesis from multiple-day and highdose chemotherapy regimens. J Natl Compr Cancer Netw 5(1):51-59

7. Saito M, Tsukuda M (2010) Review of palonosetron: emerging data distinguishing it as a novel 5-HT 3 receptor antagonist for chemotherapy-induced nausea and vomiting. Expert Opin Pharmacother 11(6): 1003-1014

8. Antiemesis (2011) NCCN clinical practice guidelines in oncology. V.3. 2011. Available from: http://www.nccn.org/professionals/ physician gls/pdf/antiemesis.pdf [last accessed 4 May 2011]

9. Roila F, Herrstedt J, Aapro M et al (2010) Guideline update for MASCC and ESMO in the prevention of chemotherapy- and radiotherapy-induced nausea and vomiting: results of the Perugia consensus conference. Ann Oncol 21(suppl 5):v232-v243

10. Eisenberg P, Figuero-Vadillo J, Zamora R, Charu V, Hajdenberg J, Cartmell A et al (2003) Improved prevention of moderately emetogenic chemotherapy induced nausea and vomiting with palonosetron, a pharmacologically novel 5HT3 receptor antagonist. Results of a phase III, single dose trial versus dolasetron. Cancer 98(11):2473-2482

11. Gralla R, Lichinitser M, Van Der Vegt S, Sleeboom H, Mezger J, Peschel C et al (2003) Palonosetron improves prevention of chemotherapy-induced nausea and vomiting following moderately emetogenic chemotherapy: results of a double-blind randomized phase III trial comparing single doses of palonosetron with ondansetron. Ann Oncol 14:1570-1577

12. Rubenstein EB, Gralla RJ, Eisenberg P (2003) Palonosetron (PALO) compared with ondansetron (OND) or dolasetron (DOL) for prevention of acute and delayed chemotherapy-induced nausea and vomiting (CINV). Combined results of two phase III trials. Proc Am Soc Clin Oncol 22:729-A2932

13. Aapro MS, Grunberg SM, Manikhas GM et al (2006) A phase III, double-blind, randomized trial of palonosetron compared with ondansetron in preventing chemotherapy-induced nausea and vomiting following highly emetogenic chemotherapy. Ann Oncol 17(9):1441-1449

14. Saito M, Aogi K, Sekine I, Yoshizawa H, Yanagita Y, Sakai H et al (2009) Palonosetron plus dexamethasone versus granisetron plus dexamethasone for prevention of nausea and vomiting during chemotherapy: a double-blind, double-dummy, randomised, comparative phase III trial. Lancet Oncol 10(2):115-124

15. Warr DG, Hesketh PJ, Gralla RJ et al (2005) Efficacy and tolerability of aprepitant for the prevention of chemotherapy-induced nausea and vomiting in patients with breast cancer after moderately emetogenic chemotherapy. J Clin Oncol 23(12):2822-2830

16. Khojasteh A, Khojasteh A, Thornburg BG et al (2009) Casopitant: a new warrior in the antiemetic crusade. Expert Opin Pharmacother 10 (8):1367-1376

17. Lorusso V, Spedicato A, Petrucelli L et al (2009) Single dose of palonosetron plus dexamethasone to control nausea, vomiting and to warrant an adequate food intake in patients treated with highly emetogenic chemotherapy (HEC). Preliminary results. Support Care Cancer 17(12):1469-1473

18. Cartmell AD, Ferguson S, Yanagihara R et al (2003) Protection against chemotherapy-induced nausea and vomiting (CINV) is maintained over multiple cycles of moderately or highly emetogenic chemotherapy by palonosetron (PALO), a potent 5-HT3 receptor antagonist (RA). Proc Am Soc Clin Oncol 22: 2003 (abstr 3041)

19. Lindley C, McCune JS, Thomason TE, Lauder D, Sauls A, Adkins $S$ et al (1999) Perception of chemotherapy side effects cancer versus non cancer patients. Cancer Pract 7:59-65

20. Basch E (2010) The missing voice of patients in drug-safety reporting. N Engl J Med 362:10

21. Einhorn LH, Brames MJ, Dreicer R et al (2007) Palonosetron plus dexamethasone for prevention of chemotherapy-induced nausea and vomiting in patients receiving multiple-day cisplatin chemotherapy for germ cell cancer. Support Care Cancer 15:1293-1300

22. Rozzi A, Nardoni CA, Corona M et al (2009) Palonosetron for the prevention of chemotherapy-induced nausea and vomiting in glioblastoma patients treated with temozolomide: a phase II study. Support Care Cancer 19:697-701

23. Musso M, Scalone R, Bonanno V, Crescimanno A, Polizzi V, Porretto F et al (2009) Palonosetron (Aloxi) and dexamethasone for the prevention of acute and delayed nausea and vomiting in patients receiving multiple-day chemotherapy. Support Care Cancer 17(2):205-209

24. Aapro M, Fabi A, Nolè F et al (2010) Double-blind, randomised, controlled study of the efficacy and tolerability of palonosetron plus dexamethasone for 1 day with or without dexamethasone on days 2 and 3 in the prevention of nausea and vomiting induced by moderately emetogenic chemotherapy. Ann Oncol May 21 (5):1083-1088, Epub 2010 Jan 15

25. Celio L, Frustaci S, Denaro A, et al (2010 June 25) Palonosetron in combination with 1-day versus 3-day dexamethasone for prevention of nausea and vomiting following moderately emetogenic chemotherapy: a randomized, multicenter, phase III trial. Support Care Cancer 19:1217-1225

26. Vardy J, Chiew KS, Galica J et al (2006) Side effects associated with the use of dexamethasone for prophylaxis of delayed emesis after moderately emetogenic chemotherapy. Br J Cancer 94:1011-1015

27. Rubenstein EB (1994) Costs and benefits of outpatient therapy. Support Care Cancer 2(5):307-311

28. Stoltz R, Cyong JC, Shah A et al (2004) Pharmacokinetic and safety evaluation of palonosetron, a 5-hydroxytryptamine-3 receptor antagonist, in U.S. and Japanese healthy subjects. J Clin Pharmacol 44:520-531

29. Wong EH, Clark R, Leung E et al (1995) The interaction of RS 25259-197, a potent and selective antagonist, with 5-HT3 receptors, in vitro. Br J Pharmacol 114(4):851-859

30. Rojas C, Stathis M, Thomas AG et al (2008) Palonosetron exhibits unique molecular interactions with the 5-HT3 receptor. Anesth Analg 107:469-478

31. Rojas C, Thomas AG, Alt J et al (2010) Palonosetron triggers 5HT(3) receptor internalization and causes prolonged inhibition of receptor function. Eur J Pharmacol 626(2-3):193-199 